\title{
Test yourself answer to question: Incidental left L5/S1 facet finding on MRI
}

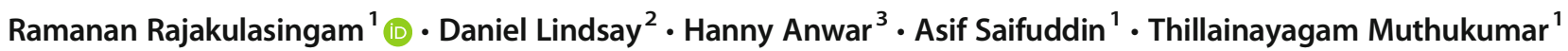

Received: 16 August 2020 / Revised: 27 September 2020 / Accepted: 30 September 2020 / Published online: 15 October 2020

(C) ISS 2020

\section{Diagnosis}

Primary aneurysmal bone cyst of the left S1 superior articular process.

\section{Discussion}

MRI (Fig. 1) shows a low T1- and heterogeneous T2weighted (T2W) signal intensity (SI) lesion arising from an expanded left S1 superior articular process. The L5/S1 facet joint was markedly irregular with multiple small cystic spaces evident on the $\mathrm{T} 2 \mathrm{~W}$ image, but no appreciable fluid-fluid levels. CT (Fig. 2) confirms a lytic lesion arising from the left S1 superior articular process with an egg-shell thin blown-out cortical appearance and no internal matrix mineralisation. The working differential diagnosis included osteoblastoma, fibrous dysplasia and less likely telangiectatic osteosarcoma.

The case presentation can be found at doi: 10.1007/s00256-020-03638-y

Ramanan Rajakulasingam

Ramanan.rajakulasingam1@nhs.net

Daniel Lindsay

daniel.lindsay1@nhs.net

Hanny Anwar

hanny.anwar@nhs.net

Asif Saifuddin

Asif.saiffudin@nhs.net

Thillainayagam Muthukumar

t.muthukumar@nhs.net

1 Department of Radiology, Royal National Orthopaedic Hospital, Brockley Hill, Stanmore, Middlesex HA7 4LP, UK

2 Department of Histopathology, Royal National Orthopaedic Hospital, Brockley Hill, Stanmore, Middlesex HA7 4LP, UK

3 Department of Orthopaedic surgery, Royal National Orthopaedic Hospital, Brockley Hill, Stanmore, Middlesex HA7 4LP, UK
Plain radiographs were unfortunately not performed. Although the lumbar region was asymptomatic, the rather unusual appearances warranted a CT biopsy with histology (Fig. 2) revealing blood-filled bony trabeculation with scattered osteoclast-like giant cells and foci of metaplastic ossification (*). Spindle cells embedded in a fibrous stroma lined the wall consistent with primary aneurysmal bone cyst $(\mathrm{ABC})$ with no atypical mitoses.

Most spinal $\mathrm{ABC}$ patients are less than 20 years old with a slight female predilection, the majority presenting with slowonset chronic back pain and a minority having underlying scoliosis. Some authors state a lumbar [1], while others report a cervical and thoracic predominance [2] for spinal ABC's. In a case series of 14 lumbar spine ABC's by Kleuver et al. [3], 9

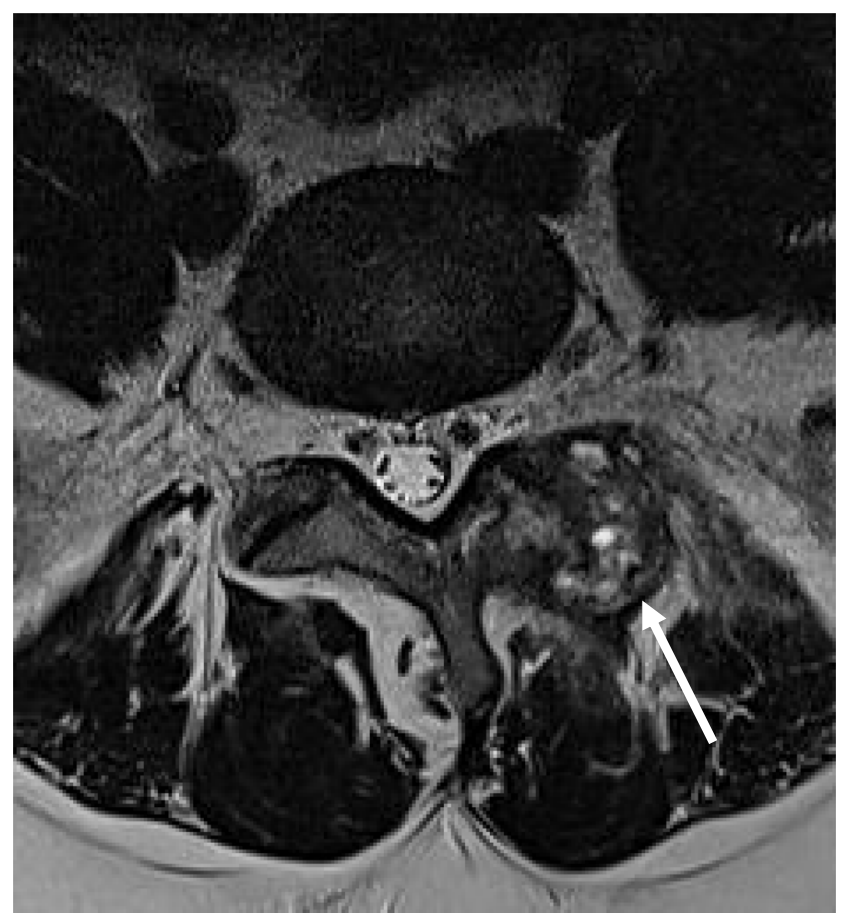

Fig. 1 Axial T2W FSE MR image showing irregular expansion of the left S1 superior articular process, which contains multiple small cystic areas but no convincing fluid-fluid levels (arrow) 


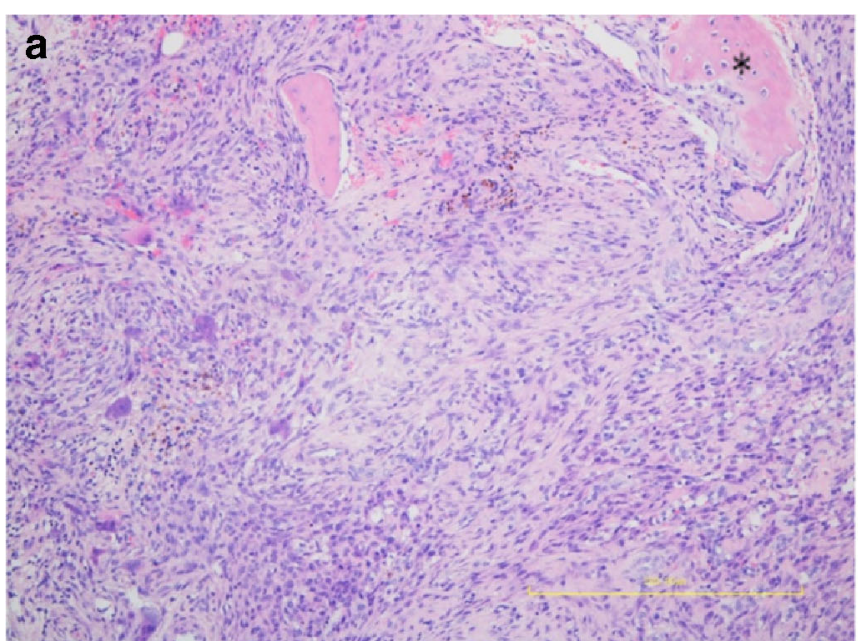

Fig. 2 Microphotographs a H\&Ex10 and b H\&Ex2. Histologically, a shows tumour composed of bland, relatively monomorphic spindle cells with a fibroblastic morphology arranged in a vague storiform architecture and embedded in a fibrous stroma. There are scattered osteoclast-like giant cells present and foci of metaplastic ossification (*). Importantly,

were in the posterior elements and 5 in the vertebral body with neural arch involvement. To the best of our knowledge, an isolated facet joint location has not been reported previously. Spinal ABC's usually arise in the neural arch, with the pedicle possibly affected first followed by the vertebral body, pedicle non-visualisation on radiographs being termed the "winking owl sign' [4]. Extension to the adjacent vertebral body through the facet joint with sparing of the disc is commonly reported and is often mistaken for malignancy.

The osteolytic appearance on CT, but lack of fluid-fluid levels, septations and cystic component on MRI, is more consistent with a solid variant rather than conventional $\mathrm{ABC}$ [5]. Solid ABC's commonly affect long tubular bones, with only 16 cases reported to date in the spine [5]. They can mimic giant cell tumour radiologically given the more solid low SI component. ABC's can be primary or secondary to an underlying lesion such as giant cell tumour, fibrous dysplasia or chondroblastoma. The lack of surrounding oedema is atypical for chondroblastoma, and the absence of a nidus and osteoid matrix was against osteoblastoma [6]. There was no internal ground glass matrix to suggest fibrous dysplasia and lack of macroscopic fluid-fluid levels and overtly aggressive features such as bone destruction also went against telangiectatic osteosarcoma [6].

The patient remained asymptomatic so no immediate surgical intervention was necessary. Generally, resection is recommended with reconstruction and spinal stabilisation if the facet joints are involved [4]. Given the high recurrence rate, the entire $\mathrm{ABC}$ wall and soft tissues lined with hypervascular membrane should be removed [4]. A slightly less invasive option includes 'curopsy' [7] where a limited curettage is done

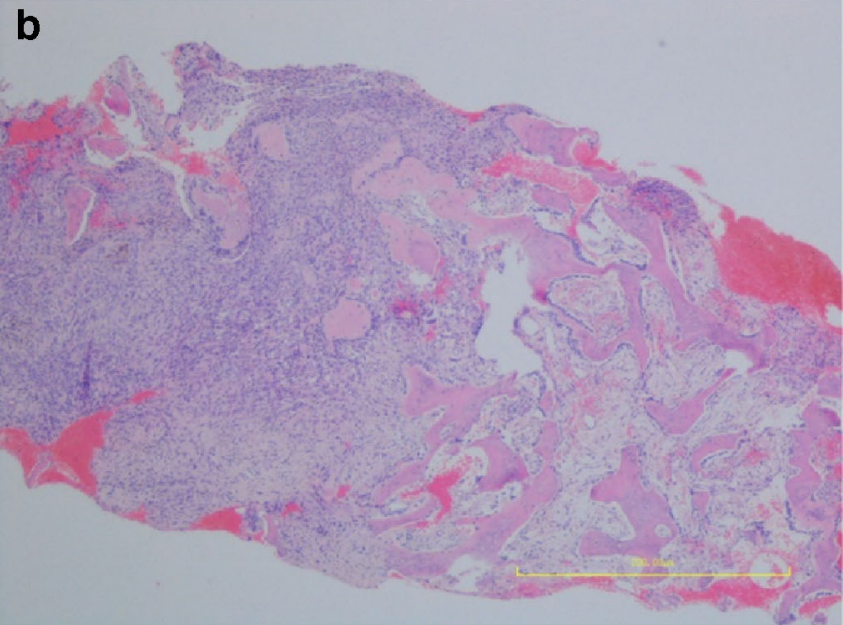

there is no significant cytological atypia and atypical mitoses. $\mathbf{b}$ shows the tumour at lower power confirming that there is no host bone permeation, with adjacent remodelled cancellous lamellar bone. Overall, these features confirm the diagnosis of an aneurysmal bone cyst

at the time of open biopsy inducing spontaneous healing with follow-up cross-sectional imaging.

\section{Compliance with ethical standards}

Conflict of interest The authors declare that they have no conflicts of interest.

\section{References}

1. Boriani S, De Iure F, Campanacci L, et al. Aneurysmal bone cyst of the mobile spine: report on 41 cases. Spine (Phila Pa 1976). 2001;26(1):27-35.

2. Vergel De Dios AM, Bond JR, Shives TC, et al. Aneurysmal bone cyst. A clinicopathologic study of 238 cases. Cancer. 1992;69(12): 2921-31.

3. de Kleuver M, van der Heul RO, Veraart BE. Aneurysmal bone cyst of the spine: 31 cases and the importance of the surgical approach. J Pediatr Orthop B. 1998;7(4):286-92.

4. Liu JK, Brockmeyer DL, Dailey AT, et al. Surgical management of aneurysmal bone cysts of the spine. Neurosurg Focus. 2003;15:4.

5. Savardekar AR, Patra D, Chatterjee D, et al. Solid variant of aneurysmal bone cyst presenting as a giant cervical mass: a clinical, radiological, histopathological dilemma. Surg Neurol Int. 2015;6(Suppl 4):S182-5.

6. Rodallec MH, Feydy A, Larousserie F, et al. Diagnostic imaging of solitary tumors of the spine: what to do and say. Radiographics. 2008;28(4):1019-41.

7. Reddy KI, Sinnaeve F, Gaston CL, et al. Aneurysmal bone cysts: do simple treatments work? Clin Orthop Relat Res. 2014;472(6):190110.

Publisher's note Springer Nature remains neutral with regard to jurisdictional claims in published maps and institutional affiliations. 